\title{
Interannual Variability of the North American Cold Air Stream and Associated Synoptic Circulations 0
}

\author{
YUKI KANNO \\ Department of Geophysics, Graduate School of Science, Tohoku University, Sendai, Japan \\ JOHN E. WALSH \\ Alaska Center for Climate Assessment and Policy, University of Alaska Fairbanks, Fairbanks, Alaska \\ TOSHIKI IWASAKI \\ Department of Geophysics, Graduate School of Science, Tohoku University, Sendai, Japan
}

(Manuscript received 18 February 2017, in final form 25 August 2017)

\begin{abstract}
In boreal winter, the cold air mass (CAM) flux of air with a potential temperature below $280 \mathrm{~K}$ forms climatological mean CAM streams in East Asia and North America (NA). This study diagnoses the interannual variability of the NA stream by an analysis of the CAM flux across $60^{\circ} \mathrm{N}$ between Greenland and the Rocky Mountains. The first empirical orthogonal function (EOF) represents the variations in intensity of the NA stream. When the first principal component (PC1) is highly positive, the central part of the NA stream is intensified, with cold anomalies east of the Rocky Mountains. At the same time, a stratospheric polar vortex tends to split or displace toward NA. PC1 is highly correlated with the tropical Northern Hemisphere pattern, implying that this pattern is associated with the intensity of the NA stream. The second EOF shows a longitudinal shift of the NA stream toward Greenland or the Rocky Mountains. A highly negative PC2 results in a cold anomaly from western Canada to the Midwestern United States and anomalous heavy snowfall in the northeastern United States. PC2 is positively correlated with the Arctic Oscillation, which suggests that the longitudinal position of the NA stream varies with the Arctic Oscillation. These results illustrate how the intensity and location of cold air outbreaks vary with large-scale modes of atmospheric variability, with corresponding implications for the predictability of winter severity in NA.
\end{abstract}

\section{Introduction}

Cold air outbreaks (CAOs) are sudden intrusions of polar cold air masses into the midlatitudes. The associated cold conditions and heavy snowfalls in the midlatitudes can severely impact human activities. The frequencies and magnitudes of CAOs dominate climate variability in the winter extratropics. In addition, CAOs play a role in heat, energy, and angular momentum balances (Garreaud 2001; Mailler and Lott 2010). Therefore, the dynamical processes underlying CAOs

Supplemental information related to this paper is available at the Journals Online website: https://doi.org/10.1175/JCLID-17-0104.s1.

Corresponding author: Yuki Kanno, kanno@dc.tohoku.ac.jp are among the keys to understanding climate variability in the winter hemisphere.

North America (NA) experiences vigorous CAO activity during the Northern Hemisphere winter (Garreaud 2001). NA CAOs generally occur east of the Rocky Mountains in connection with an upper-level trough over the central United States (Hartjenstein and Bleck 1991). Strong CAOs sometimes reach the subtropics and cause extensive damage to agricultural products in the southern part of the United States (Rogers and Rohli 1991). Previous studies have addressed the time evolutions of CAOs in this region (e.g., Dallavalle and Bosart 1975; Konrad 1996, 1998; Schultz et al. 1998; Walsh et al. 2001; Cellitti et al. 2006). Synoptically, CAOs are characterized by a southward migration of a cold surface anticyclone from Canada to the Gulf of Mexico or the East Coast of the United States. In the middle troposphere, an amplified 
trough on the downstream side of the Rocky Mountains and a ridge over the western United States initiate a southward migration of the surface anticyclone. North Atlantic blocking and North Pacific blocking can lead to the persistence of this pattern, resulting in extreme cold winters (Marinaro et al. 2015). In addition, cold anomalies in NA associated with increased CAO activity are followed often by a weak stratospheric polar vortex (Thompson et al. 2002; Cellitti et al. 2006; Kolstad et al. 2010). While most of the previous studies focus on the features of CAOs on intraseasonal time scales, the present paper provides a climatic perspective by addressing the characteristics of interannual variability of CAO activity.

Monthly mean anomalous circulation patterns are characterized by teleconnections (Wallace and Gutzler 1981), which are modes of variability consisting of correlated spatial anomalies of the large-scale circulation. Previous studies have shown that the Pacific-North America (PNA) pattern, tropical Northern Hemisphere (TNH) pattern, western Pacific pattern (WP), North Atlantic Oscillation (NAO), and Arctic Oscillation (AO) affect climate variability over NA during winter (Rogers 1984; Thompson and Wallace 1998; Thompson and Wallace 2001; Walsh et al. 2001; Cellitti et al. 2006; Marinaro et al. 2015). Figure 1 shows the 500-hPa manifestations of these large-scale modes of variability. The PNA and TNH patterns are related to variations in sea surface temperature in the tropical Pacific Ocean, especially El Niño-Southern Oscillation (ENSO) (Yu et al. 2012). The positive phase of the PNA pattern, which is strongly tied to the warm ENSO, is associated with increased occurrences of CAOs. The TNH pattern, which occurs in association with the eastern Pacific ENSO (Yu et al. 2015), includes a deep trough over Hudson Bay and a cold anomaly over eastern NA (Mo and Livezey 1986). Marinaro et al. (2015) found that the cold winter of 2013/14 was related to the positive TNH pattern, for which the index reached its second highest value since 1951 (Ogi et al. 2016). On the other hand, Baxter and Nigam (2015) and Lee et al. (2015) showed that temperature anomalies of 2013/14 were mainly contributed by the negative WP pattern; the WP index was at its lowest value since 1979. The NAO variations influence the large-scale atmospheric circulation from NA to Europe (Hurrell 1995). Negative NAO winters are associated with CAOs and cold anomalies over the eastern and central United States (Rogers 1984; Walsh et al. 2001; Cellitti et al. 2006). The $\mathrm{AO}$ is a hemispheric-scale seesaw of surface pressure between the Arctic and extratropics and is related to climate anomalies over a wide range of the Northern Hemisphere (Thompson and Wallace 1998). The negative phase of the AO tends to bring cold anomalies over midlatitudes (Thompson and Wallace 1998; Thompson and Wallace 2001).

Time means of the flux of cold air mass (CAM) below a designated potential temperature depict distinct cold air mass streams in East Asia and NA for the Northern Hemispheric winter (Iwasaki et al. 2014). The East Asian stream flows eastward over northern Eurasia, turns southeastwards around Siberia, and disappears over the western North Pacific Ocean. The NA stream originates from the Arctic Ocean, strengthens over the northern part of NA, flows toward the east coast of NA, and disappears over the North Atlantic Ocean. The interannual variability of the East Asian stream has been decomposed into distinct empirical orthogonal function (EOF) modes, which have greater amplitudes on the eastern or western sides of the East Asian stream (Abdillah et al. 2017). The variability of the CAM flux on the western and eastern sides is associated with the strength of the Siberian high and Aleutian low, respectively, and the fluxes on the two sides correspond to different synoptic situations on interannual as well as on intraseasonal time scales (Shoji et al. 2014; Abdillah et al. 2017). By contrast, variability of the NA stream on either the interannual or the intraseasonal time scale has not been studied yet. The present study evaluates and diagnoses the interannual variability of the NA stream and associated synoptic circulations. We conduct an EOF analysis of the interannual variability of the NA stream and then perform a composite analysis to reveal the synoptic circulations associated with the obtained EOF modes.

This paper is organized as follows. Section 2 describes the data and methods. Characteristics of the climatology and interannual variability of the NA stream are presented in section 3, and synoptic circulations associated with variations of the NA stream in section 4. Conclusions are summarized in section 5 .

\section{Data and methods}

Six-hourly temperatures, horizontal wind components, and surface pressures from the Japanese 55-Year Reanalysis (JRA-55) are used to calculate the CAM amount and its flux (Kobayashi et al. 2015). The data are archived at $1.25^{\circ} \times 1.25^{\circ}$ horizontal resolution and 37 pressure levels ranging from 1000 to $1 \mathrm{hPa}$. To focus on the midwinter season, January means of these variables for the period 1959-2016 are analyzed. In addition, geopotential height and mean sea level pressure (SLP) are used for composite analyses. Monthly mean teleconnection indices from the NOAA CPC website (http://www.cpc.noaa.gov/) are used. The teleconnection indices used in this study are the AO index, the NAO 
(a)

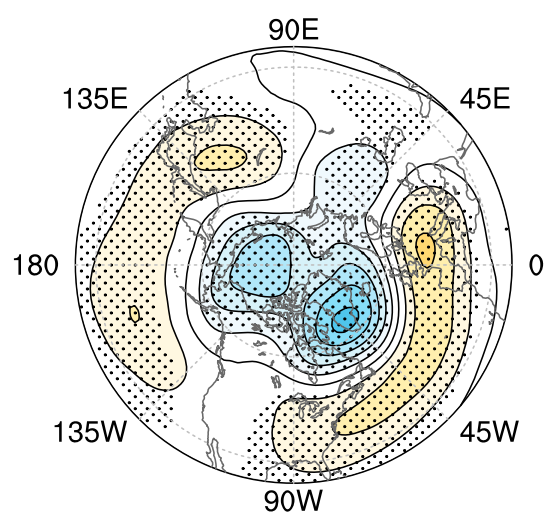

(c) TNH

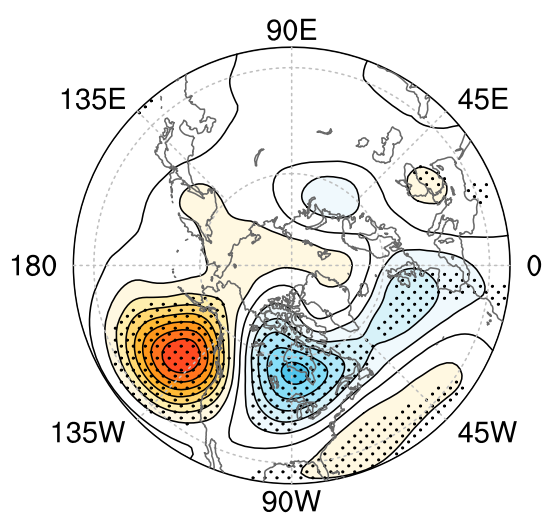

(e) WP

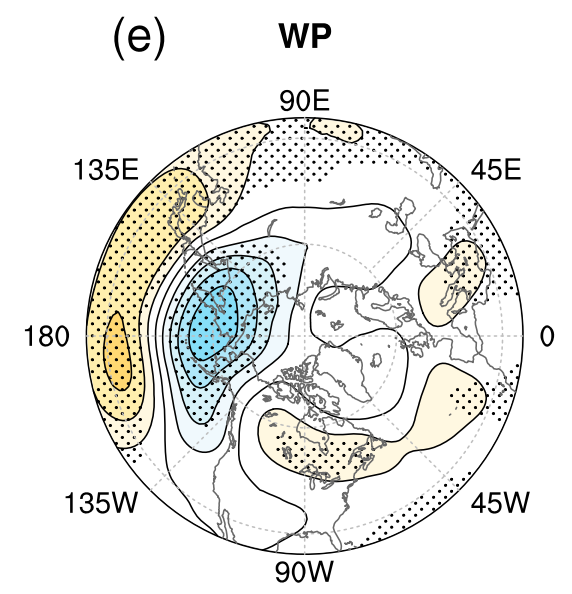

(b) NAO

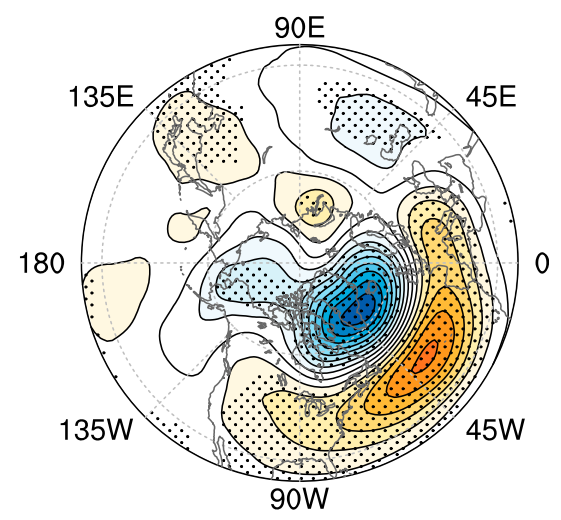

(d) PNA

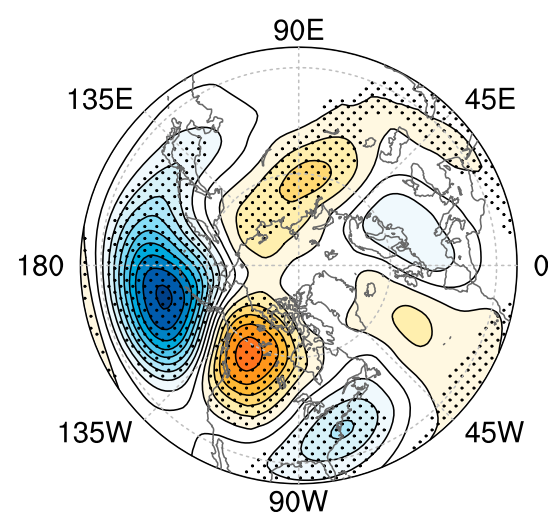

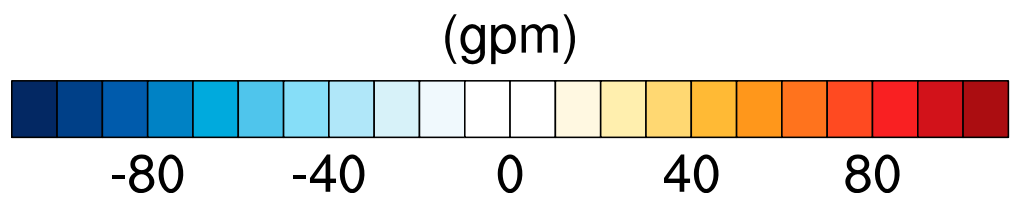

FIG. 1. Regressions of 500-hPa geopotential height against the (a) AO, (b) NAO, (c) TNH, (d) PNA, and (e) WP indices for January. Stippled regions satisfy 95\% confidence levels. 
index, the Niño-3 index, the Niño-4 index, the Niño-3.4 index, the Pacific decadal oscillation (PDO) index, the PNA index, the TNH index, the WP index, and the Atlantic multidecadal oscillation (AMO) index. Definitions of these indices are provided at the NOAA CPC website. Daily snowfall data from the Historical Climate Network $(\mathrm{HCN})$ are used to examine the relationship between the variability of the NA stream and snowfall in the eastern United States (Easterling et al. 1999). The HCN (ftp:// ftp.ncdc.noaa.gov/pub/data/ghcn/daily) provides a highquality dataset of daily meteorological observations from surface stations in the United States. A total of 805 of the 1218 stations have snowfall data for the period 1959-2016 and were used in this study. Daily snowfall data were converted to monthly accumulated snowfall data by summing the daily values for each month.

In this study, CAM is the vertical (pressure) depth of the atmosphere below a designated potential temperature $\theta_{T}$. The designated potential temperature is set at $280 \mathrm{~K}$, following previous studies. CAM amount (DP) at each location is defined as the pressure difference between the ground surface and the $\theta_{T}$ surface:

$$
\mathrm{DP} \equiv p_{s}-p\left(\theta_{T}\right),
$$

where $p$ is pressure and $p_{s}$ is the pressure at the ground surface. The mass flux (MF) of CAM is defined as

$$
\mathbf{M F} \equiv \int_{p\left(\theta_{T}\right)}^{p_{s}} \mathbf{v} d p
$$

where $\mathbf{v}$ is a horizontal wind vector. The diabatic change rate of CAM amount $G\left(\theta_{T}\right)$ is defined as

$$
\left.G\left(\theta_{T}\right) \equiv \frac{\partial p}{\partial \theta} \dot{\theta}\right|_{\theta_{T}},
$$

where $\dot{\theta}$ is the diabatic heating rate. CAM amount, CAM flux, and diabatic change rate of CAM amount satisfy a conservation equation [Eq. (3) in Iwasaki et al. 2014]. To measure the "coldness" of CAM amount, a thermodynamic parameter called negative heat content (NHC, denoted as $\vartheta$ )

$$
\vartheta \equiv \int_{p\left(\theta_{T}\right)}^{p_{s}}\left(\theta_{T}-\theta\right) d p
$$

is also analyzed. The NHC considers the vertical temperature profile within the CAM. Vertical integration in (2) and (4) is performed using mandatory pressure level data at each 6-hourly time step of the reanalysis. The diabatic change rate of CAM amount is estimated as a residual of the conservation relation [Eq. (3) in Iwasaki et al. 2014] at each 6-hourly time step.
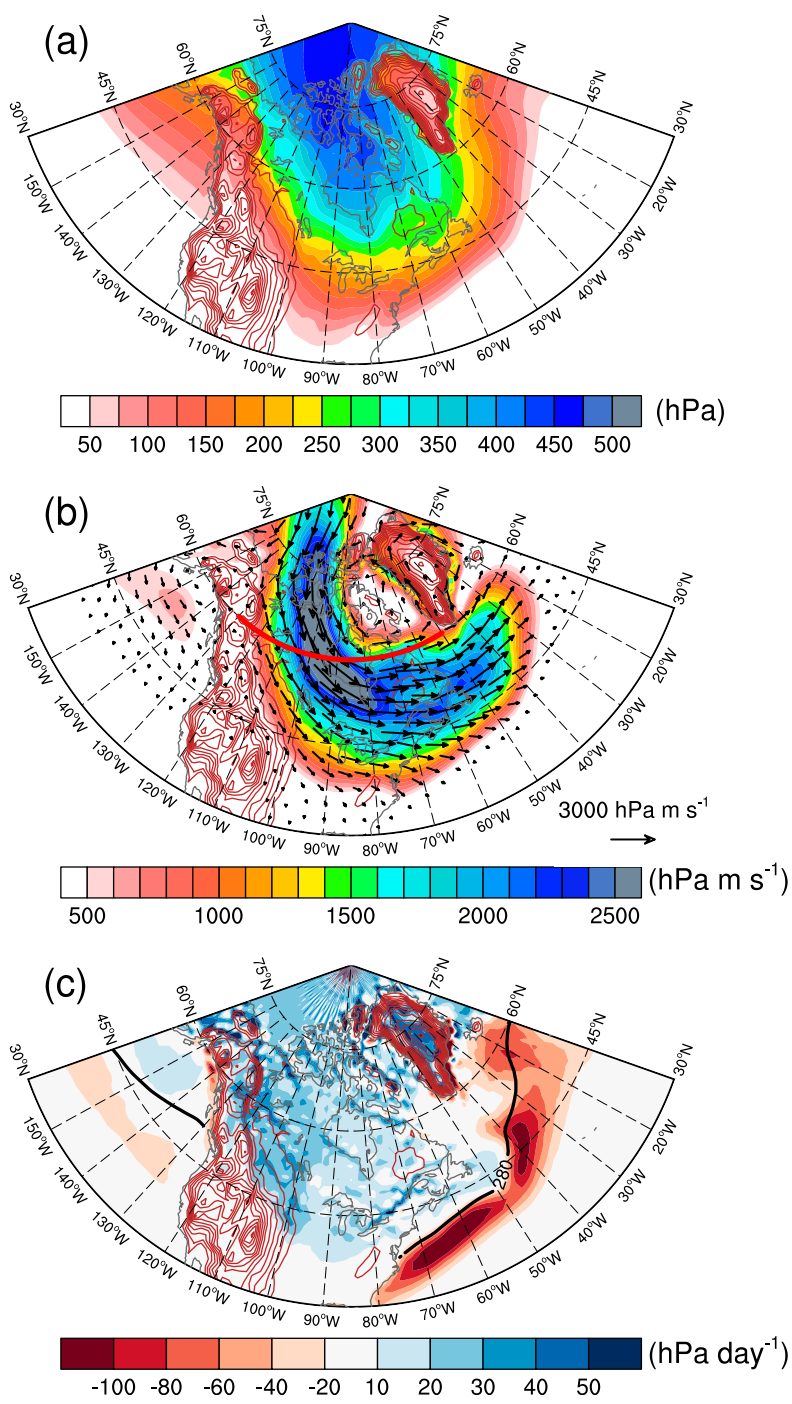

FIG. 2. Climatological distribution of (a) CAM amount (shading; $\mathrm{hPa}$ ), (b) NA cold airstream (shading is the magnitude of the CAM flux; $\mathrm{hPams}^{-1}$ ), and (c) genesis/loss rate of CAM amount $\left(\mathrm{hPa} \mathrm{day}^{-1}\right)$ in January. Vectors in (b) are CAM flux (hPa m s${ }^{-1}$ ). The black line in (c) is the $280-\mathrm{K}$ isotherm of SST. Brown contours denote topography with interval of $500 \mathrm{~m}$. The red line in (b) ranges from $50^{\circ}$ to $130^{\circ} \mathrm{W}$ at $60^{\circ} \mathrm{N}$, where meridional CAM flux across this line is used for the EOF analysis.

Interannual variability of the NA stream is examined by an EOF analysis of meridional CAM flux. The EOF analysis is conducted with the departures from January mean values of CAM flux across $60^{\circ} \mathrm{N}$ between $50^{\circ}$ and $130^{\circ} \mathrm{W}$ (red line in Fig. 2b). The EOFs are therefore onedimensional functions of longitude. The longitudinal range extends from Greenland westward to the Rocky Mountains. A total of $58 \mathrm{yr}$ (1959-2016) of January data are used for the analysis. To identify synoptic patterns associated with the EOF modes, composite analyses are 
performed for the corresponding time-varying principal components (PCs), and relationships with atmospheric teleconnections are estimated from correlations between the PCs and teleconnection indices. Statistical significance of the results is tested by a two-tailed Student's $t$ test.

\section{Characteristics of the NA stream}

\section{a. Climatology}

In the midlatitudes of the Northern Hemisphere winter, zonal mean equatorward transport of cold air is observed below the potential temperature of about $280 \mathrm{~K}$, while zonal mean poleward transport of warm air occurs above $280 \mathrm{~K}$ (Iwasaki et al. 2014). Thus, the potential temperature of $280 \mathrm{~K}$ is used for the threshold of the CAM flux. Figure 2a shows the climatological (19592016) patterns of CAM amount over NA for January. CAM increases with latitude and reaches about $400 \mathrm{hPa}$ over the northern part of Canada. CAM expands to the east coast of NA, as it does in East Asia (Fig. 4a in Iwasaki et al. 2014), consistent with stationary thermal trough in the middle troposphere. It is worth noting that the CAM amount has been decreasing significantly for this period (Kanno et al. 2016), and this decreasing trend agrees well with the trend of the cold-air pool, defined as the extent of the $-5^{\circ} \mathrm{C}$ isotherm at $850 \mathrm{hPa}$ (Martin 2015). Figures $2 b$ and $2 c$ show climatologies of CAM flux in terms of the intensity and diabatic change rates of CAM amount, respectively. The area of CAM genesis extends from the sea ice regions in the Arctic Ocean to $\mathrm{NA}$, with a rate of about $40 \mathrm{hPa} \mathrm{day}^{-1}$ (Fig. 2c). Over NA, the cold airstream is distinct (Fig. 2b). The detailed structure of the NA stream can be summarized as follows: it originates over the Arctic Ocean and flows southward between Greenland and the Rocky Mountains, undergoing further development by diabatic cooling. The core of the stream is located at about $100^{\circ} \mathrm{W}$, where the intensity reaches approximately $2400 \mathrm{hPa} \mathrm{m} \mathrm{s}^{-1}$. The southward flow is mainly between about $80^{\circ} \mathrm{W}$ and the Rocky Mountains, which act as a barrier and direct a southward penetration of the stream (Hartjenstein and Bleck 1991) (Fig. 3a). Another weak peak of equatorward flux is at $60^{\circ} \mathrm{W}$ with a magnitude of approximately $500 \mathrm{hPa} \mathrm{m} \mathrm{s}^{-1}$. The primary stream gradually turns toward the east after passing through $60^{\circ} \mathrm{N}$ latitude and then reaches the east coast of NA. The southern flank of the stream covers the northern part of the United States. Over the western Atlantic Ocean, CAM disappears at a substantial rate of about $100 \mathrm{hPaday}^{-1}$ due to strong diabatic heating from the Gulf Stream (Fig. 2c). The disappearance region of CAM extends from the southwestern part of the Atlantic Ocean to the northeast and (a) Climatology of meridional CAM flux @60N

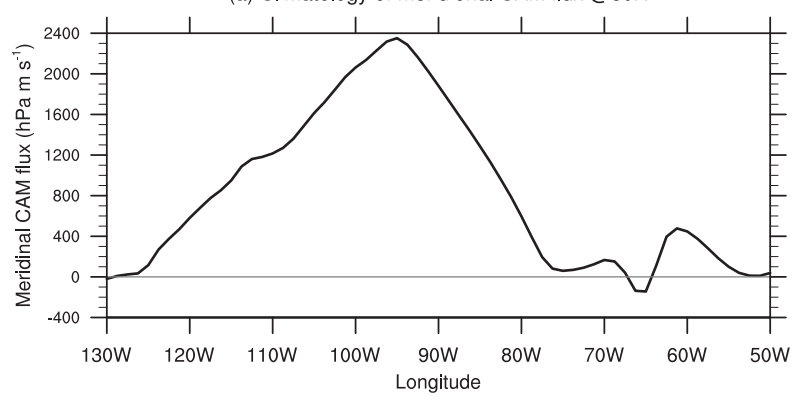

(b) EOF modes

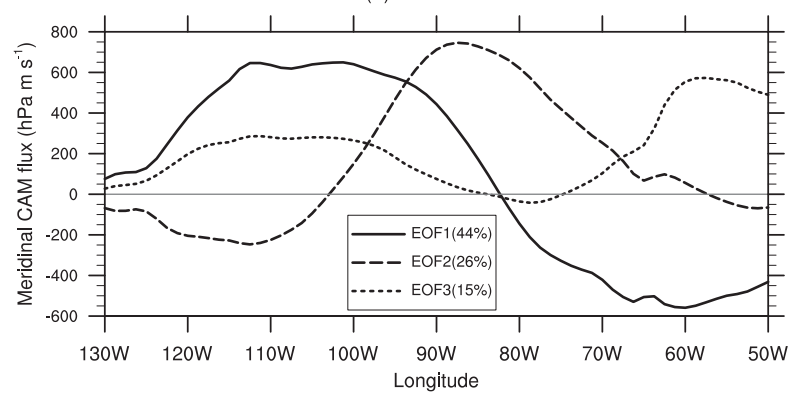

FIG. 3. (a) Climatology of CAM flux at $60^{\circ} \mathrm{N}$ over NA and (b) loading patterns of the first three EOF modes of meridional CAM flux at $60^{\circ} \mathrm{N}$ between $50^{\circ}$ and $130^{\circ} \mathrm{W}$ in January. Vertical axes are reversed, so that southward flux is positive. Explained variances are shown in the legend.

aligns just south of the $280-\mathrm{K}$ surface temperature. This disappearance region corresponds to the position of the Atlantic storm track, where considerable amounts of heat are released from the Gulf Stream, which in turn affects the atmospheric circulations (Minobe et al. 2008).

A metric of the magnitude of the NA stream is the meridional CAM flux integrated across $60^{\circ} \mathrm{N}$ between $50^{\circ}$ and $130^{\circ} \mathrm{W}$ (red line in Fig. $2 \mathrm{~b}$ ), the region where the flow is primarily southward between Greenland and the Rocky Mountains. The climatological mean value of the integrated meridional CAM flux divided by the gravitational acceleration in this region is approximately $3.8 \times 10^{10} \mathrm{~kg} \mathrm{~s}^{-1}$, which accounts for half of the global equatorward CAM flux at $60^{\circ} \mathrm{N}$ (Kanno et al. 2015). [The division of the domain average of the zonally integrated CAM flux by the gravitational acceleration, resulting in units of kilograms per second, is done for consistency with previous studies (e.g., Kanno et al. 2016)]. The magnitude of the NA stream is about $70 \%$ of the EA stream, which is measured by the equatorward CAM flux at $45^{\circ} \mathrm{N}$ between $90^{\circ} \mathrm{W}$ and $180^{\circ}$ (Shoji et al. 2014). The meridional distribution of the meridional CAM flux integrated between $50^{\circ}$ and $130^{\circ} \mathrm{W}$ is a maximum at $60^{\circ} \mathrm{N}$ while the flux between $90^{\circ} \mathrm{E}$ and $180^{\circ}$ is at a maximum at $45^{\circ} \mathrm{N}$ (figure not shown). The standard deviation of interannual variability of the NA stream is 
(a) January PC1

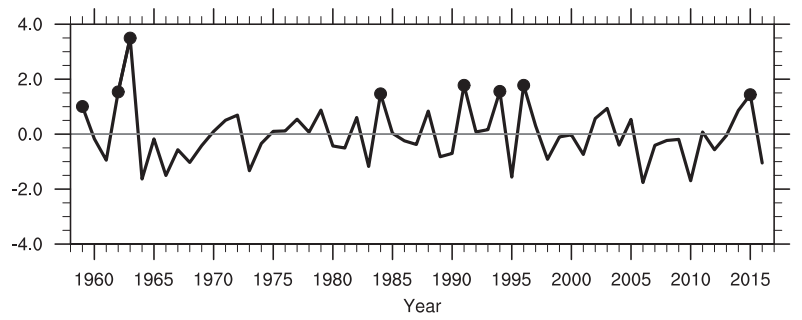

(b) January PC2

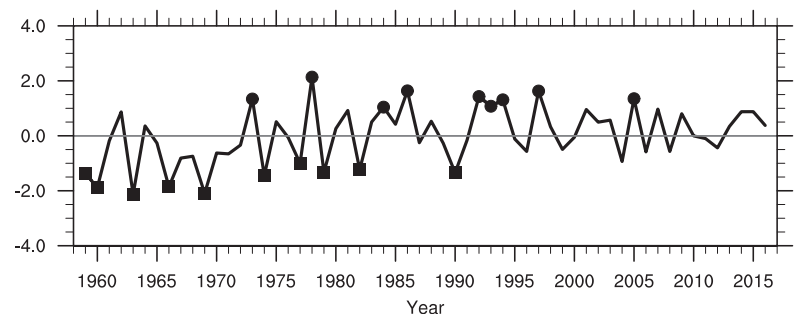

FIG. 4. Principal components of the EOF modes: (top) PC1 and (bottom) PC2. Years with PCs $>+1.0$ are denoted by filled circles in (a) and (b), and years with PC2 $<-1.0$ are denoted by filled squares in (b).

approximately $1.3 \times 10^{10} \mathrm{~kg} \mathrm{~s}^{-1}$, which is about $30 \%$ of the climatological means.

\section{b. EOF analysis of NA stream variability}

Interannual variability of the NA stream is quantified by an EOF analysis of the meridional CAM flux across $60^{\circ} \mathrm{N}$ between $50^{\circ}$ and $130^{\circ} \mathrm{W}$. Figure $3 \mathrm{~b}$ displays the spatial patterns of three leading EOF modes. Note that the vertical axis is reversed so that equatorward flux is positive. The first EOF mode is characterized by a dipole with a nodal point near $80^{\circ} \mathrm{W}$. A broad positive anomaly at $90^{\circ}-$ $110^{\circ} \mathrm{W}$ and a negative anomaly at $60^{\circ}-70^{\circ} \mathrm{W}$ have almost the same maximum magnitude, about $600 \mathrm{hPa} \mathrm{m} \mathrm{s}^{-1}$. The broad positive anomaly is located west of the main peak of climatological CAM flux at $95^{\circ} \mathrm{W}$ (Figs. 3a,b). The first mode explains about $44 \%$ of the total variance of the meridional CAM flux in this region and is clearly separated from other modes. Almost the same spatial structure and explained variance are obtained for this mode if DJFmean data are used instead of only January data.

The interannual variability of the NA stream is further shown in a composite of the CAM flux for this mode. Using a threshold criterion of +1.0 for the first PC (PC1), eight positive PC1 winters (denoted by black circles in Fig. 4a) are selected, and these are called the highly positive PC1 winters hereafter. They include the remarkable positive year of 1963, which is one of the coldest Januaries in NA's recorded history (O'Connor 1963). Figure 5a illustrates composites of the CAM flux and its intensity for the highly positive $\mathrm{PC} 1$ winters. The CAM fluxes denoted as vectors are composite means, whereas the flux magnitudes denoted as color shadings are composite anomalies.

The highly positive $\mathrm{PC} 1$ corresponds to an enhancement of the NA stream (Fig. 5a), as the location of the strongest CAM flux anomaly is consistent with the core of the climatological mean NA stream. Anomalous strong equatorward flow is observed west of $90^{\circ} \mathrm{W}$, and anomalous strong eastward flow in the $45^{\circ}-60^{\circ} \mathrm{N}$ band. CAM mostly flows toward the northwestern Atlantic Ocean, but partly returns to the polar region west of Greenland. This return flow is consistent with the anomalous negative CAM flux on the eastern side (Fig. 3b). Although anomalous strong equatorward CAM flux is observed over the western side of NA, anomalous northward CAM flux near Greenland partially offsets the equatorward CAM flux between $50^{\circ}$ and $130^{\circ} \mathrm{W}$, which results in only a modest correlation $(r=$ 0.33 ) between the PC1 and the magnitude of the NA stream. It is worth noting that CAM flux anomalies for the highly negative $\mathrm{PC} 1$ winters, defined as the years in which PC1 time series is below -1.0, are almost opposite to those of the highly positive PC1 winters, indicating a weakening of the climatological mean NA stream when $\mathrm{PC} 1$ is strongly negative (figure not shown).

The second EOF mode shows a zonal dipole, with a substantial positive anomaly around $90^{\circ} \mathrm{W}$ reaching about $700 \mathrm{hPa} \mathrm{m} \mathrm{s}^{-1}$ and a weak negative anomaly west of $110^{\circ} \mathrm{W}$ (Fig. $3 \mathrm{~b}$ ). It explains about $26 \%$ of the total variance of the meridional CAM flux in this region and is clearly distinct from the other modes. The spatial structure of this mode is similar when DJF-mean data are used instead; however, in that case it is not clearly separated from the third EOF mode. About $70 \%$ of the total variance is explained by the first two EOF modes.

The composite of the CAM flux clearly reveals that the second EOF mode is the east-west shift of the NA stream. Similar to the procedure with PC1, 9 positive second PC (PC2) winters (denoted by black circles in Fig. 4b) and 10 negative PC2 winters (denoted by black squares in Fig. 4b) were selected by applying +1.0 and -1.0 criteria for PC2 . The selected 9 positive (10 negative) PC2 winters are called the highly positive (negative) winters hereafter. The composite mean of the PC2 score is $1.44(-1.57)$ for the highly positive (negative) PC2 winters. During highly positive (negative) PC2 winters, the NA stream is shifted toward Greenland (the Rocky Mountains) (Figs. 5b,c). During the highly positive PC2 winters, the NA stream intensifies on the eastern side of the climatological mean position, and the magnitude of the CAM flux anomalies reaches about $1500 \mathrm{hPa} \mathrm{m} \mathrm{s}^{-1}$ (Fig. 5b). During the highly negative PC2 winters, on the other hand, the NA stream is intensified on its western flank (i.e., immediately east of the Rocky Mountains) and suppressed on its eastern flank (Fig. 5c). When PC2 is strongly negative, the positive anomalies of 
(a) Composite of CAM flux \& intensity(anomaly) +PC1

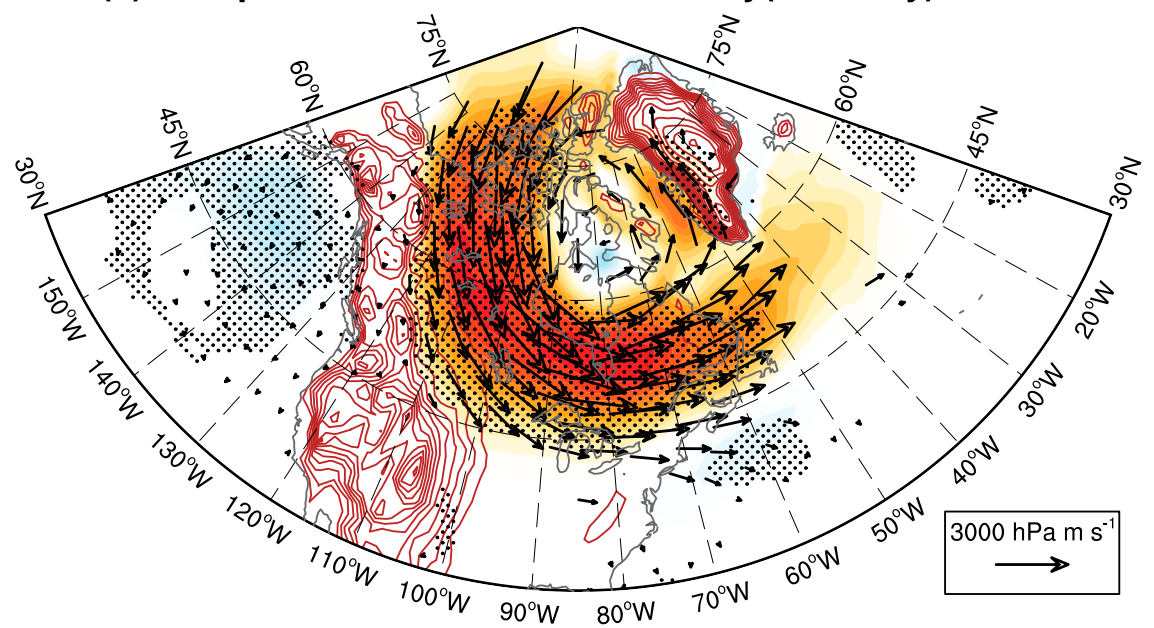

(b) Composite of CAM flux \& intensity(anomaly) +PC2

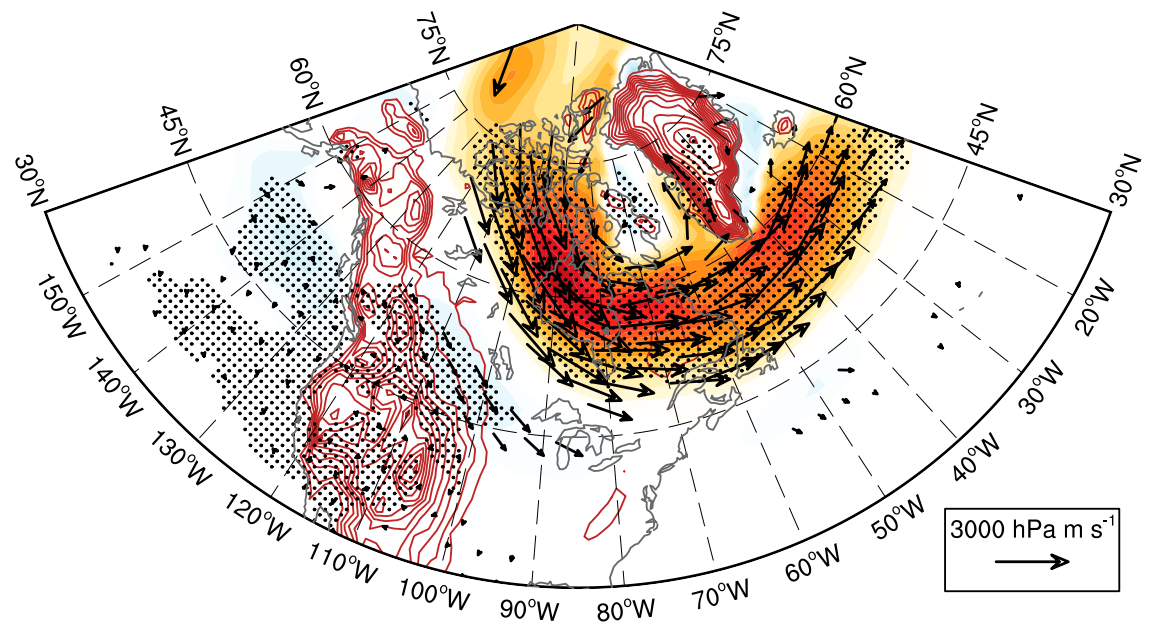

$\left.(\mathrm{hPa} \mathrm{m} \mathrm{s})^{-1}\right)$

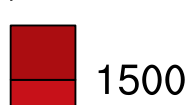

(c) Composite of CAM flux \& intensity(anomaly) -PC2

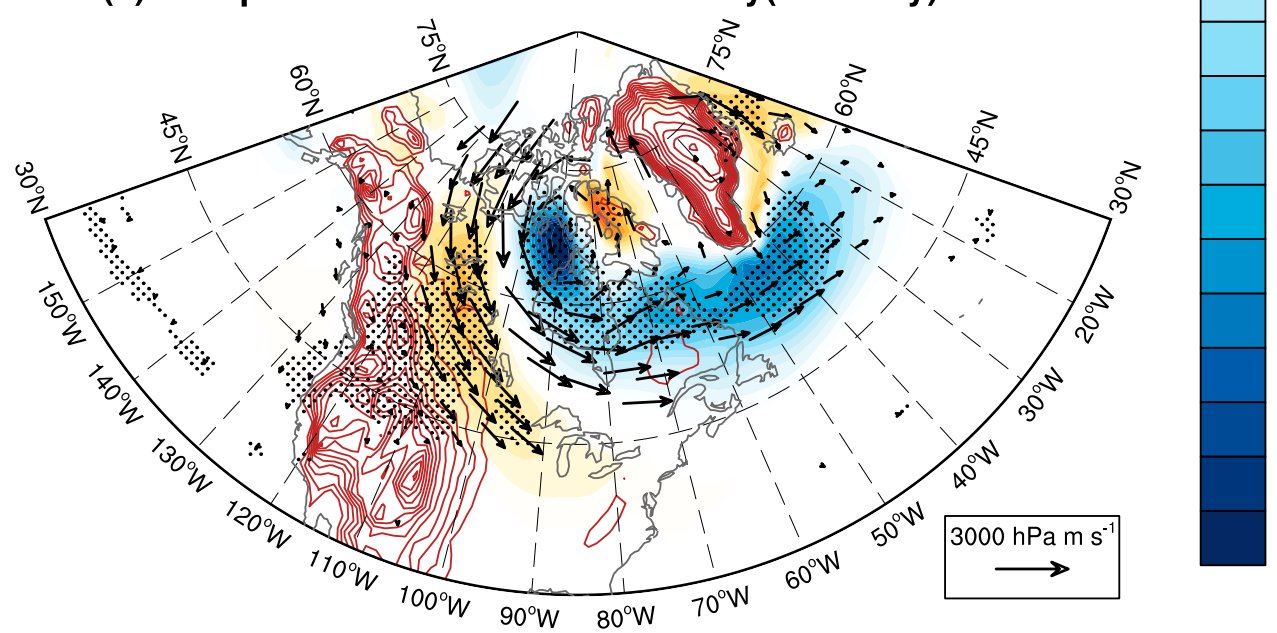

FIG. 5. Composite means of the CAM flux (vectors) and composite anomalies of the magnitude of the CAM flux (color shading) for (a) highly positive PC1, (b) highly positive PC2, and (c) highly negative PC2 winters. Brown contours denote topography with contour interval of $500 \mathrm{~m}$. Stippled regions satisfy $95 \%$ confidence levels. Vectors are shown where either zonal or meridional component satisfies $95 \%$ confidence levels. 

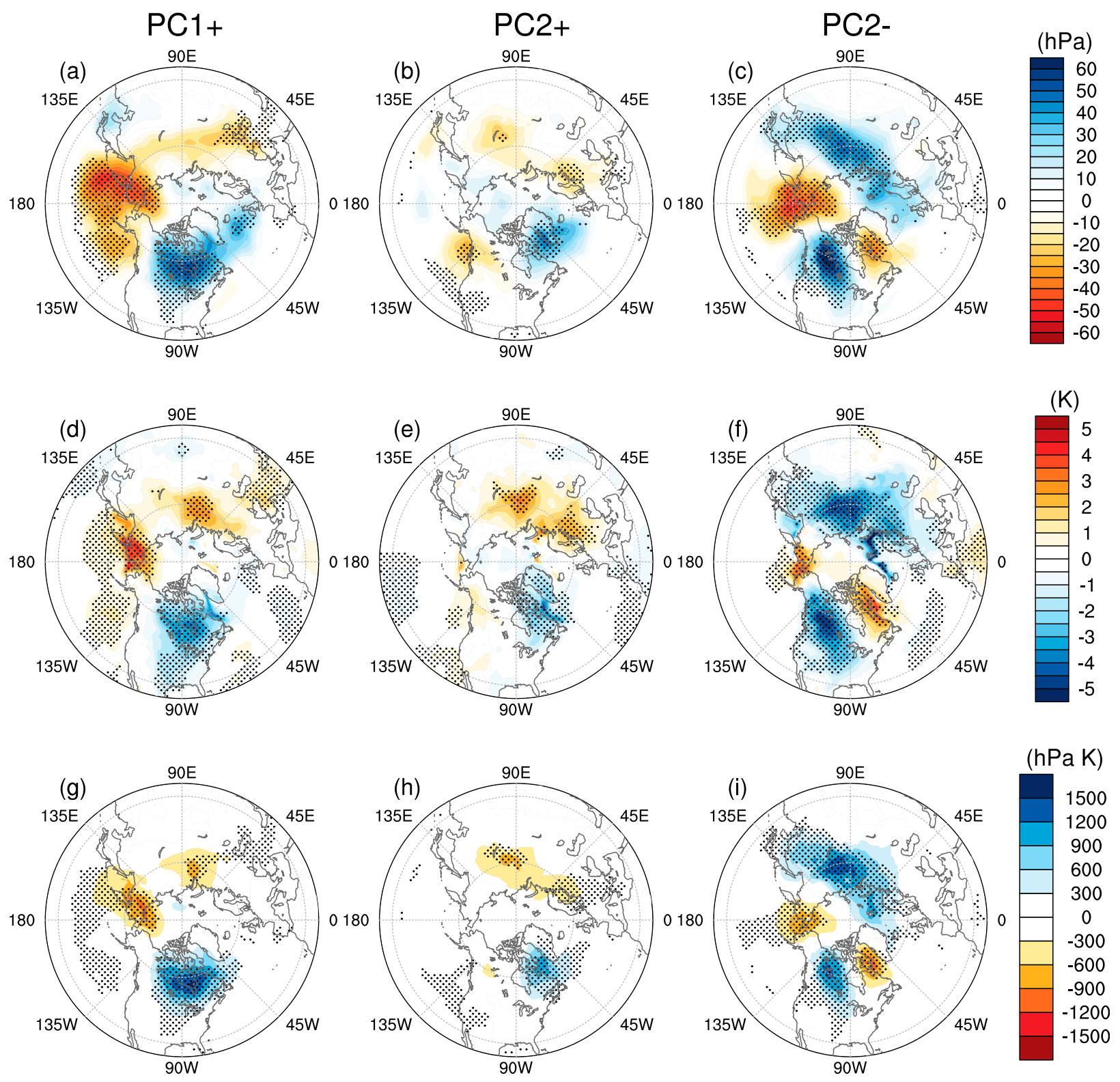

FIG. 6. Composite anomalies of (a)-(c) CAM amount, (d)-(f) surface temperature, and (g)-(i) NHC, for (left) highly positive PC1, (middle) highly positive PC2, and (right) highly negative PC2 Januaries. Stippled regions satisfy $95 \%$ confidence levels.

CAM flux amplitude are narrower and weaker than in the other composite winters, but the CAM flux extends farther south to the Great Lakes. The total equatorward CAM flux in the NA stream varies with $\mathrm{PC} 2$, increasing (decreasing) by $0.72 \times 10^{10} \mathrm{~kg} \mathrm{~s}^{-1}$ for PC2 scores of $+1.0(-1.0)$.

\section{Synoptic circulations associated with the EOF modes}

\section{a. The first EOF mode}

This section identifies synoptic circulation patterns associated with the EOF modes. Figure 6 illustrates composite anomalies of CAM amount, surface temperature, and NHC. For the highly positive PC1, the composite mean of the PC1 score is 1.76 for the 8 selected years. The highly positive $\mathrm{PC} 1$ composite shows positive $\mathrm{CAM}$ anomalies extending from the central and eastern part of Canada to the Midwest of the United States, and negative anomalies over the northern Pacific Ocean (Fig. 6a). The broadly distributed cold anomaly is consistent with the enhancement of the NA stream. Anomalous CAM patterns agree well with anomalous surface temperature patterns, although some differences are found over the North Pacific and North 
TABLE 1. Correlation coefficients between teleconnection indices and PCs. One and two asterisks (* and **) denote $95 \%$ and $99 \%$ confidence levels, respectively.

\begin{tabular}{lcc}
\hline & PC1 & PC2 \\
\hline AO & -0.02 & $0.49^{* *}$ \\
NAO & -0.04 & $0.48^{* *}$ \\
Niño-3 & -0.23 & -0.19 \\
Niño-4 & -0.10 & $0.26^{*}$ \\
Niño-3.4 & -0.21 & 0.21 \\
PDO & -0.07 & 0.22 \\
PNA & -0.10 & $0.38^{* *}$ \\
TNH & $0.63^{* *}$ & -0.13 \\
WP & $-0.33^{*}$ & 0.02 \\
AMO & -0.05 & -0.11 \\
\hline
\end{tabular}

Atlantic Oceans, where surface temperature anomalies are weak (cf. Figs. 6a and 6d). The largest negative surface temperature anomaly observed near Hudson Bay is about $-3.7 \mathrm{~K}$ (standard deviation is $2.1 \mathrm{~K}$ ). The temperature anomaly over the Midwestern United States is about $-2 \mathrm{~K}$ (standard deviation is $1.1 \mathrm{~K}$ ). The spatial pattern of the NHC composite (Fig. 6g) is consistent with those of CAM amount and surface temperature. A small difference is that the southward extension of NHC is weaker than that of CAM amount because NHC is more sensitive to temperature in the lower troposphere. The spatial patterns of NHC agree well with CAM amount computed using a lower threshold potential temperature (e.g., $245 \mathrm{~K}$ ), thereby reflecting the distribution of extremely colder air mass.

Table 1 shows correlations between the PCs and atmospheric teleconnection indices. PC1 is positively correlated with the TNH pattern $(r=0.63)$ at the $99 \%$ confidence level and negatively correlated with the WP pattern $(r=-0.33)$. Previous studies have pointed out the relationship between cold winters in NA and these indices (Baxter and Nigam 2015; Marinaro et al. 2015; Ogi et al. 2016). Although the TNH pattern is related to the eastern Pacific ENSO (Yu et al. 2015), no significant correlation is found with ENSO indices. In addition, neither the AO nor the NAO shows significant correlation with PC1.

Figure 7 shows composite means and anomalies of SLP, 500-hPa geopotential height (Z500), and 50-hPa geopotential height (Z50) for the months with large PC magnitudes. In the middle troposphere $(500 \mathrm{hPa})$, there is a distinct wave train that extends zonally from the North Pacific to the western Atlantic Ocean, with a negative anomaly over Hudson Bay and positive anomalies over the east coast of NA and the Bering Sea extending to the west coast of NA (Fig. 7d). These patterns are also observed in the SLP anomalies (Fig. 7a), so the structure is barotropic. The midtropospheric wave train from the Gulf of Alaska to the western Atlantic Ocean via the Hudson Bay reflects the positive phase of the TNH pattern (Fig. 1c), and these anomalies are associated with a southward shift of the tropospheric polar vortex to the NA sector. In addition, a positive anomaly over the northeastern Pacific and a negative anomaly over the Hudson Bay found in the TNH pattern are consistent with the geopotential height anomalies in Fig. 7d, implying an amplification of climatological mean planetary waves over NA (Fig. 1c of Takaya and Nakamura 2013). An amplified ridge over the northeastern Pacific and a trough over Hudson Bay form an eastward pressure gradient force, strengthening the central part of the NA stream in a geostrophic sense. Strong positive anomalies of Z500 over the Bering Sea are consistent with the negative phase of the WP pattern (Fig. 1e). Corresponding to the strong meridional pressure gradient along the east coast of NA (Fig. 7d) and meridional temperature gradient (Fig. 6d), the uppertropospheric jet stream over the western Atlantic Ocean strengthens and shifts northward (figure not shown).

Stratospheric anomalies for the highly positive PC1 winters are characterized by a displacement or a split of the polar vortex toward NA (Fig. 7g). There is a substantial negative anomaly over Hudson Bay as well as weak positive anomalies over the Sea of Okhotsk and over Eurasia extending from northwestern Europe to western Siberia. Over central Siberia, on the opposite side of the pole from the NA sector, the geopotential height anomaly is weakly positive and not statistically significant. To quantify the relationship between the variations in PC1 and the polar vortex, the polar vortex index (PVI) is defined as the normalized Z50 anomaly averaged over the red box in Fig. 7g. Table 2 shows correlation coefficients between the PVI and PC1. The correlation between the PVI and PC1 is -0.55 , significant at the $99 \%$ confidence level. The negative correlation means that the polar vortex tends to deepen over the NA sector with increasing PC1. The anomaly of the polar vortex can be classified into a split and a displacement, as we show by decomposing the Z50 anomaly field into zonal wavenumber- 1 and -2 components for each year, and then calculating zonal wavenumber-1 and -2 components of the PVI [PVI(WN1) and PVI (WN2)]. Both zonal wavenumber-1 and -2 components of the PVI have strong correlations with PC1 $(r=-0.61$ and $r=-0.48)$. A split of the polar vortex is also deduced from Fig. $7 \mathrm{~g}$, where the anomaly is not significant over the central Siberia because positive anomalies from the displacement of the stratospheric polar vortex offset negative anomalies associated with the split. These results indicate that the polar vortex tends to displace or split toward NA during highly positive PC1. 

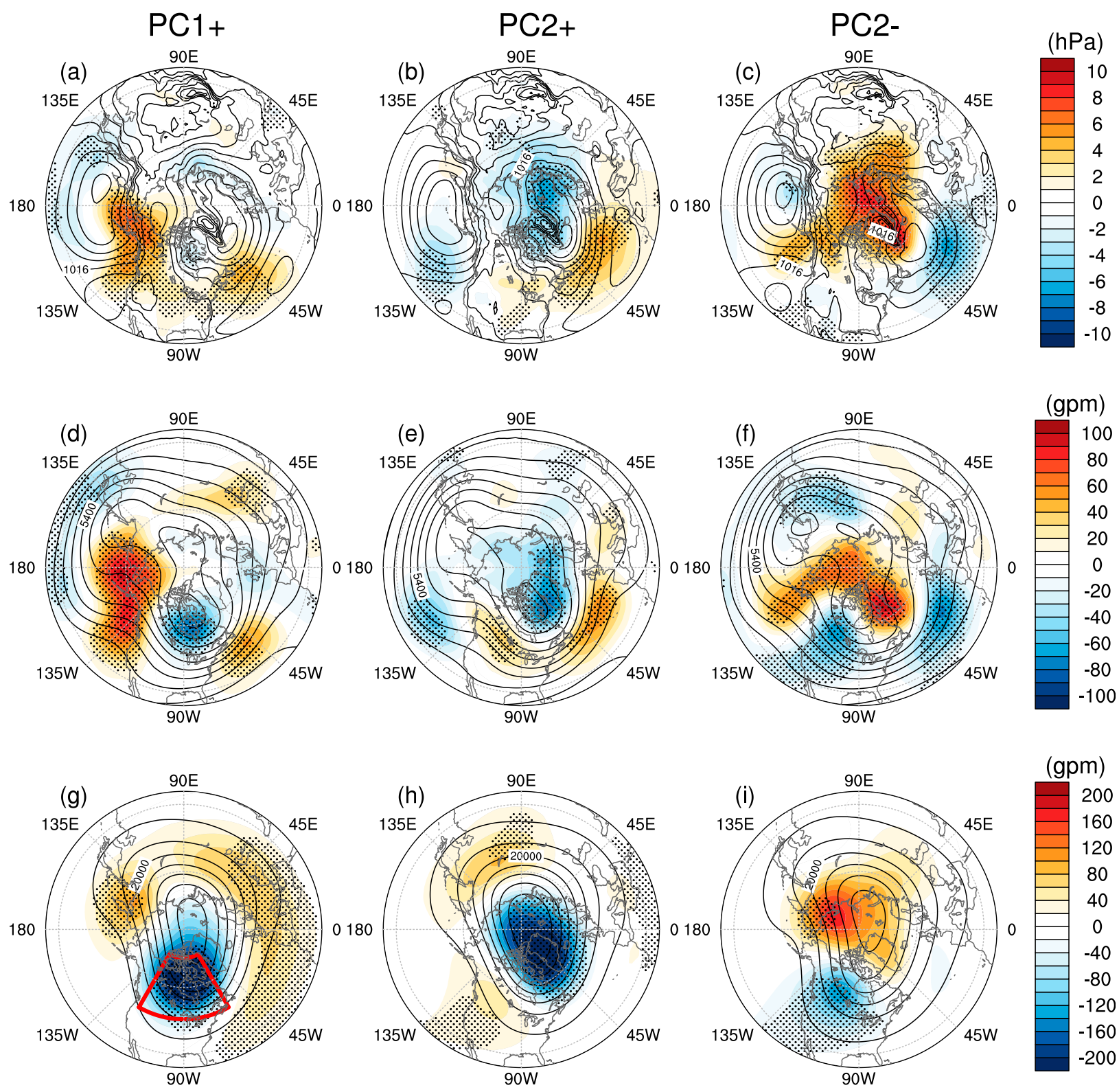

FIG. 7. As in Fig. 6, but for (a)-(c) sea level pressure, (d)-(f) 500-hPa geopotential height, and (g)-(i) 50-hPa geopotential height. Colors denote anomaly magnitudes and black contours denote composite means with intervals of $4 \mathrm{hPa}$ for (a)-(c), $100 \mathrm{gpm}$ for (d)-(f), and $100 \mathrm{gpm}$ for (g)-(i). Geopotential height anomaly averaged over the red box in (g) is used for the calculation of the PVI.

\section{b. The second EOF mode}

Differences in the position of the NA stream have substantial impacts on the location of cold anomalies. The highly positive PC2 corresponds to an enhanced cold anomaly over the Labrador Sea and a suppressed anomaly over the north-central Siberian and eastern Europe (Figs. 6b,e). Although slight differences are found in the Eurasian continent, the anomalies of CAM, surface temperature, and NHC are generally consistent (Figs. 6c,f,i). Because the NA stream does not extend to the United States for the highly positive PC2 winters (Fig. 5b), no temperature deviation is observed there. On the other hand, the highly negative PC2 winters have strong cold anomalies over the western parts of NA and northern Eurasia, and warm anomalies over eastern Canada and the northern Pacific Ocean (Figs. 6c,f). The cold anomaly is about $-5 \mathrm{~K}$ (standard deviation is $3.2 \mathrm{~K}$ ) over western Canada and extends to the Midwest of the United States, where anomalous equatorward CAM flux is observed (Fig. 5c). It also extends west of the Rocky Mountains, consistent with an occurrence of California 
TABLE 2. Correlation coefficients between the PVI and the PC1. PVI(WN1) and PVI(WN2) are zonal wavenumber-1 and -2 components of the PVI, respectively. Two asterisks (**) denote $99 \%$ confidence levels.

\begin{tabular}{lc}
\hline \hline & PC1 \\
\hline PVI & $-0.55^{* *}$ \\
PVI(WN1) & $-0.61^{* *}$ \\
PVI(WN2) & $-0.48^{* *}$ \\
\hline
\end{tabular}

CAOs (Grotjahn and Faure 2008). The other cold anomalies with highly negative PC2 are over northern Eurasia and East Asia, where anomalies are not pronounced in the highly positive PC2 winters (Figs. 6b,e). Although total equatorward CAM flux in the NA stream is suppressed in the highly negative PC2 winters, these winters tend to be cold in the midlatitudes of NA. The changeable route of the NA stream determines the location of cold and warm winter temperatures in NA.

Figure 8 shows composite anomalies of cumulative snowfall in January over the northeastern United States. For the highly negative PC2 winters, above-normal cumulative snowfall is observed in the western part of Michigan, the northern part of New York, Vermont, New Hampshire, and Maine (Fig. 8). In particular, Buffalo, New York, shows more cumulative snowfall than normal years by $25.7 \mathrm{~cm}$ (standard deviation is $17.8 \mathrm{~cm}$ ), which suggests an enhancement of lake effect snowfall (Burnett et al. 2003). Positive snowfall anomalies are consistent with anomalously low temperature (Fig. 6f) and northwesterly surface wind, caused by SLP contours that favor airflow from northwest to southeast (Fig. 7c). Prominent anomalies of snowfall are not observed in the composite for highly positive PC1 or highly positive PC2 Januaries (figure not shown). This is because the corresponding SLP gradients are relatively weak downstream of the Great Lakes (Fig. 7a), although negative surface temperature anomalies are significant (Fig. 6d).

The variation of $\mathrm{PC} 2$ is characterized by the $\mathrm{AO}$ (and NAO). PC2 is positively correlated with the AO ( $r=$ $0.49)$ and NAO $(r=0.48)$, and both correlations satisfy $99 \%$ confidence level (Table 1). The anomalous temperature patterns are also consistent with the AO, although the highly positive $\mathrm{PC} 2$ winters show only a weak signal over Eurasia (Figs. 6e,f). PC2 has a positive correlation with the PNA pattern and the Niño-4 index as well, consistent with the excitation of the PNA pattern by the Pacific ENSO. Although PC1 is characterized by the TNH pattern, there is no significant correlation between $\mathrm{PC} 2$ and the TNH patterns.

Middle tropospheric circulation anomalies for the highly positive (negative) PC2 winters are characterized by negative (positive) Z500 anomalies over the polar

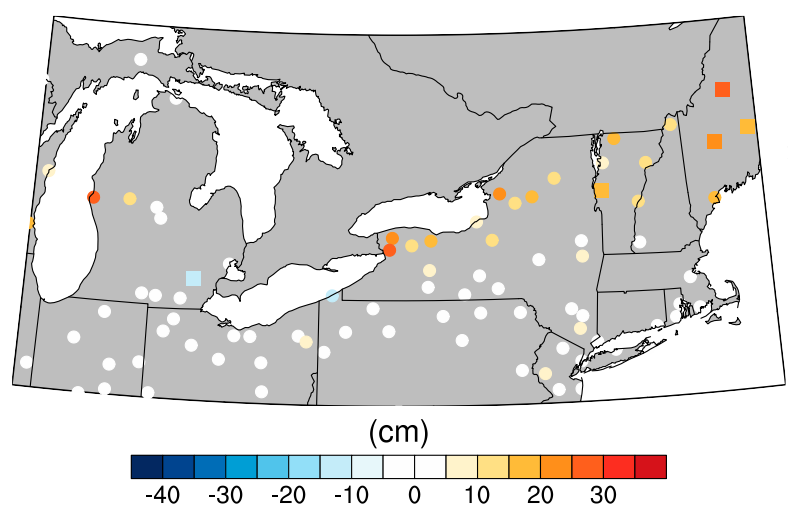

FIG. 8. Composite anomalies of January cumulative snowfall for highly negative $\mathrm{PC} 2$. The stations represented by squares satisfy $95 \%$ confidence levels.

region and the northeastern Pacific Ocean, and positive (negative) Z500 anomalies over western NA and the midlatitude Atlantic Ocean (Figs. 7e,f). For the highly positive PC2 winters, positive Z500 (SLP) anomalies over central Canada and a negative anomaly extending from the Labrador Sea to the Barents Sea create an anomalous eastward pressure gradient force over eastern Canada (Figs. 7b,e), geostrophically shifting the NA stream to the east (Fig. 5b). For the highly negative PC2 winters, on the other hand, positive Z500 anomalies over the North Pacific and negative anomalies over western NA shift the NA stream westward. These anomalies are consistent with SLP anomalies (Figs. 7b,c), indicating a barotropic structure. Anomalous negative (positive) SLP patterns in the Arctic reflect the positive (negative) phase of the AO (Thompson and Wallace 1998). A north-south shift of the upper tropospheric jet in the Atlantic Ocean is implied by the Z500 anomalies over the Atlantic Ocean (Figs. 7e,f and 1b), consistent with NAO. In addition, the highly negative PC2 winters show negative Z500 anomalies over East Asia, and the spatial patterns have a zonal wavenumber-3 structure. These results imply that the AO and NAO are associated with longitudinal shifts of the NA stream. In the stratosphere, strengthening (weakening) of the stratospheric polar vortex is evident for highly positive (negative) PC2, reflecting an AO structure (Figs. 7h,i). This finding supports the results of previous studies, which have found that CAOs in the midlatitudes of NA tend to occur during weak polar vortex events (Thompson et al. 2002; Cellitti et al. 2006; Kolstad et al. 2010).

\section{c. Physical interpretation of the EOF modes}

Since EOF modes are mathematical constructs and are affected by (spatial and temporal) orthogonality constraints, physical interpretations can be open to question. To address the physical validity of the EOFs 
(a) Correlation of meridional CAM flux @60N

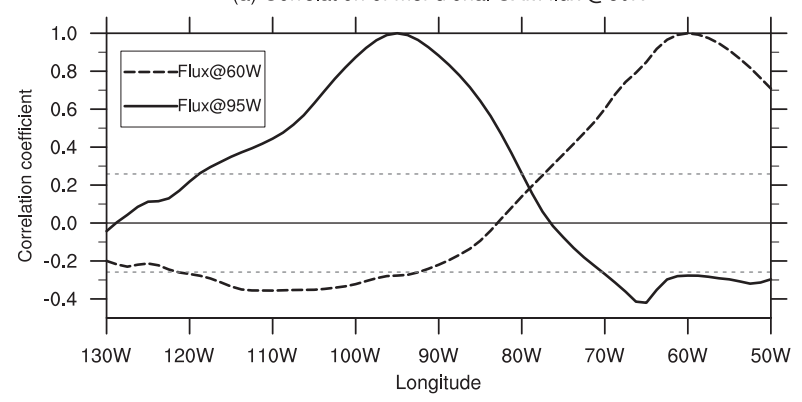

(b) Rotation of EOF modes (promax)

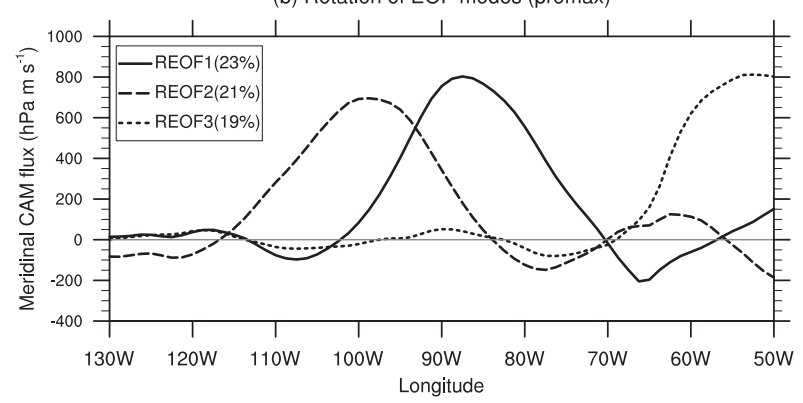

FIG. 9. (a) Temporal correlation of meridional CAM flux at $60^{\circ} \mathrm{N}$ vs two single points: $60^{\circ} \mathrm{N}, 95^{\circ} \mathrm{W}$ (solid) and $60^{\circ} \mathrm{N}, 95^{\circ} \mathrm{W}$ (broken). (b) Loadings of first three modes of Promax rotation of EOFs at $60^{\circ} \mathrm{N}$ between $50^{\circ}$ and $130^{\circ} \mathrm{W}$. Horizontal dotted lines in (a) represent $95 \%$ confidence levels. Explained variances of leading modes are provided in the legend of (b).

presented here, we correlated the CAM fluxes at EOF maxima-minima with the fluxes elsewhere in the domain. Figure 9a shows correlations of meridional CAM flux at $60^{\circ} \mathrm{N}$ with the concurrent fluxes at two single points: $60^{\circ} \mathrm{N}, 95^{\circ} \mathrm{W}$ and $60^{\circ} \mathrm{N}, 60^{\circ} \mathrm{W}$. The longitudes of these two points correspond to the peaks of climatological mean meridional CAM flux and the broad maximum/minimum of EOF1 (Figs. 3a,b). The correlations show that the meridional CAM fluxes at these two points correspond to distinct longitudinal patterns on either side of $80^{\circ} \mathrm{W}$, indicating that the eastern and western sides of the stream do not covary, consistent with the dominance of the western maximum in Fig. 3a. The time series of the meridional CAM flux at $60^{\circ} \mathrm{N}$, $95^{\circ} \mathrm{W}$ has a significant correlation with the PC1 $(r=$ 0.71 ). In addition, composite anomalies of surface temperature, CAM amount, SLP, and geopotential height at $500 \mathrm{hPa}$ in the $10 \mathrm{yr}$ with the strongest meridional CAM flux at $60^{\circ} \mathrm{N}, 95^{\circ} \mathrm{W}$ (figure not shown) closely resemble the composites for the highly positive PC1 (Figs. 6a, 7a, d). Composite anomalies of surface temperature and CAM amount for the strongest (weakest) years of the CAM flux at $60^{\circ} \mathrm{N}, 60^{\circ} \mathrm{W}$ have some common features with those for highly positive (negative) PC2 (Fig. 6e; see also Figs. S1 and S2 in the online supplemental material). For both the highly positive PC2 and strong eastern peak years, anomalous negative surface temperature is observed over the Labrador Sea. For years of weak meridional CAM flux at the peak of the eastern stream, anomalous negative surface temperatures are located over central Canada and the United States. This pattern represents an eastward shift relative to negative PC2 years.

To examine whether the second EOF mode is a result of the orthogonality constraint, an oblique rotation of the EOF modes was performed (Navarra and Simoncini 2010). Specifically, the first five EOF modes where subjected to an oblique Promax rotation. The first rotated Promax mode shows a peak at $85^{\circ} \mathrm{W}$ (Fig. 9b), and the PC of the first Promax mode is highly correlated with the nonrotated PC2 $(r=0.93)$. The second rotated Promax mode has a peak at $100^{\circ} \mathrm{W}$, but this peak does not extend to the west. The PC of the second Promax mode is highly correlated with the nonrotated PC1 $(r=$ 0.86 ). We conclude that the nonrotated $\mathrm{PC} 1$ and $\mathrm{PC} 2$ are not strongly impacted by the orthogonality constraint.

\section{d. Relationship between CAM amount and the TNH or AO pattern}

We showed in Table 1 that PC1 (PC2) has a significant correlation with the TNH (AO) index. Here, these relations are further analyzed. Figure 10 illustrates CAM amount and CAM flux regressed against the TNH and AO indices. The CAM amount regressed against the TNH index agrees well with the composite for the highly positive PC1 winters (Fig. 6a), with positive anomalies covering the region east of the Rocky Mountains. Regression of the CAM flux shows a cyclonic circulation with the center over the Hudson Bay (Fig. 10c). This anomalous cyclonic circulation pattern is consistent with the negative Z500 anomaly there (Fig. 8c) and indicates a strengthening of the NA stream at its climatological mean position during its positive phase. The strengthening of the central part of the NA stream is explained by geostrophic balance, as discussed above. These results imply that the impact on temperature variability in NA by the $\mathrm{TNH}$ pattern is through a modulation of the PC1 phase of the NA stream.

The AO influences NA climate in winter by modulating the route of the NA stream. CAM regressed against the AO shows a north-south dipole over NA, with a positive anomaly over northeastern Canada and a negative anomaly over the central and eastern United States (Fig. 10b). The location of the positive anomaly is generally consistent with the composite for the PC2 winters (Fig. 6c). However, the center of the negative anomaly in Fig. 6c is located over western Canada with a weak extension into the eastern United States. Regression of the CAM flux shows an anomalous circumpolar circulation 
$\mathrm{TNH}$
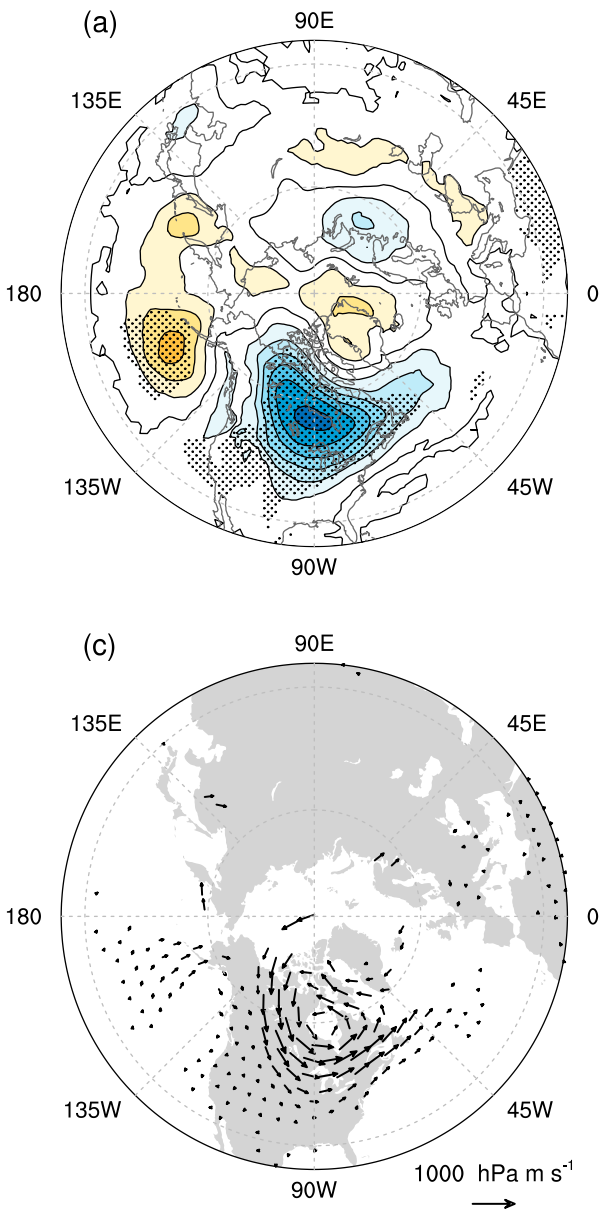

$\mathrm{AO}$
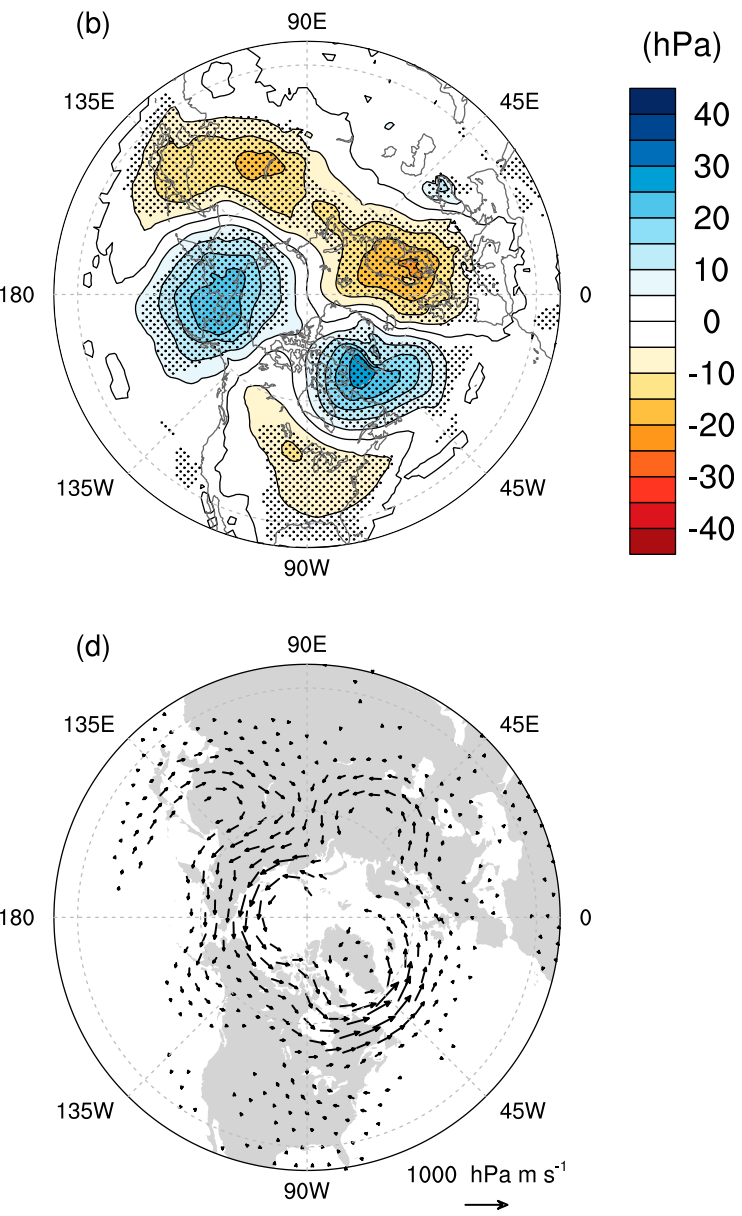

FIG. 10. Regression coefficients of (a),(b) CAM amount and (c),(d) CAM flux, regressed against (left) the TNH index and (right) the AO index. Stippled regions in (a) and (b) satisfy $95 \%$ confidence levels. Vectors in (c) and (d) are shown where either the zonal or meridional component satisfies $95 \%$ confidence levels.

over the high latitudes. An anomalous equatorward CAM flux is located over northeastern Canada (Fig. 10d), which is consistent with an anomalous eastward pressure gradient force in this region (Fig. 7a). Over the Midwest of the United States, a weak anomalous northward flow is observed. These signals are consistent with a shift of the NA stream toward Greenland for highly positive PC2 and enhanced southward penetration of the stream into the central United States for highly negative PC2. These results confirm that the AO's impacts on the temperature variability over NA are through a modulation of the route of the NA stream.

\section{Conclusions}

The interannual variability of the NA cold airstream and associated synoptic circulations has been studied in an EOF analysis of meridional CAM flux. In boreal winter, the NA stream flows southward between Greenland and the Rocky Mountains, turns eastward after passing through $60^{\circ} \mathrm{N}$ latitude, and then reaches the east coast of NA. The meridional CAM flux integrated across $60^{\circ} \mathrm{N}$ between $50^{\circ}$ and $130^{\circ} \mathrm{W}$ is a metric for the magnitude of the NA stream. The climatological mean value of the integrated meridional CAM flux in this region is about $3.8 \times 10^{10} \mathrm{~kg} \mathrm{~s}^{-1}$, which accounts for half of the global equatorward CAM flux at $60^{\circ} \mathrm{N}$.

The interannual variability of the NA stream is well explained by the first two EOF modes of the meridional CAM flux across $60^{\circ} \mathrm{N}$ between Greenland and the Rocky Mountains. The first EOF mode shows a zonal dipole with its primary center located at $80^{\circ} \mathrm{W}$ and represents a variation in the intensity of the NA stream. This mode explains about $44 \%$ of the total variance of 
meridional CAM flux at $60^{\circ} \mathrm{N}$ between $50^{\circ}$ and $130^{\circ} \mathrm{W}$. The composite CAM flux for the eight winters with the most strongly positive $\mathrm{PC} 1$ shows enhancement of the NA stream at its climatological mean position, with cold anomalies extending from the central and eastern Canada to the Midwest of the United States. The circulation pattern for highly positive PC1 is consistent with the TNH pattern. An anomalous strong climatological mean ridge over the northeastern Pacific and a trough over the Hudson Bay strengthen the core of the NA stream. The AO is almost irrelevant to this mode (i.e., to the variation of the NA stream at its climatological mean position).

The second EOF mode shows a zonal dipole with a substantial positive anomaly at $90^{\circ} \mathrm{W}$ and a weak negative anomaly west of $105^{\circ} \mathrm{W}$. This mode explains about $26 \%$ of the total variance of meridional CAM flux at $60^{\circ} \mathrm{N}$ between $50^{\circ}$ and $130^{\circ} \mathrm{W}$. Nine and ten winters were selected for the highly positive and negative PC2 winters, respectively. Highly positive (negative) PC2 shifts the NA stream to the region around Greenland (the Rocky Mountains). Positive (negative) PC2 increases (decreases) the net equatorward CAM flux across $60^{\circ} \mathrm{N}$ between $50^{\circ}$ and $130^{\circ} \mathrm{W}$. Highly positive PC2 winter patterns show a cold anomaly over the eastern part of Canada. During highly negative PC2 winters, cold conditions are intensified over western NA and suppressed over eastern Canada. For highly negative PC2 winters, January cumulative snowfall is enhanced in the northeastern United States, which is due in part to the lake effect. The circulation patterns for this mode are characterized by the $\mathrm{AO}$ and NAO. Our results indicate that the changeable route of the NA stream dominates the climate variability in the NA winter when the second EOF mode is active. These findings improve the understanding of cold winters in NA and imply that improved predictions of the $\mathrm{AO}$ and NAO are important for forecasts of severe winter conditions in NA. Specifically, better prediction of the TNH pattern will enhance forecasts of the intensity of CAOs, and better prediction of the AO will improve forecasts of the location of North American CAO events in as well as forecasts of snow in the eastern United States.

Our study showed that variations in both $\mathrm{PC} 1$ and $\mathrm{PC} 2$ have relations with the stratospheric polar vortex, but their stratospheric signals are different. The variations in PC2 are related to a change (weakening or strengthening) of the stratospheric polar vortex. This result is consistent with previous studies, which showed that cold events in midlatitude tend to occur when the stratospheric polar vortex is weak (Thompson and Wallace 2001; Thompson et al. 2002). A displacement, as well as a split of the polar vortex toward the NA sector, tends to occur during the highly positive PC1. This distinction between displacements and splits of the polar vortex has not emerged from previous studies.

Although this study focused on the interannual variability of the NA stream, CAM and CAO changes in the context of longer-time-scale global warming are an important topic in the climate research. Total hemispheric CAM amount in the Northern Hemispheric winter has been significantly decreasing since the mid-twentieth century, whereas hemispheric-scale CAO change is not statistically significant in the boreal winter (Kanno et al. 2016). Studies on the externally forced changes of CAM amount and CAM flux over North America are necessary to shed light on this discrepancy and to understand how regional climate change will affect the occurrence of extreme cold events.

Finally, we note that much attention has recently been given to the connection between Arctic sea ice variation and weather in the midlatitudes (e.g., Overland et al. 2015). For example, Kug et al. (2015) showed that anomalous warmth in the East SiberianChukchi Sea favors cold winters in NA. Sea ice variability is a potentially important source of predictability of the circulation over NA on intraseasonal to seasonal time scales. The relationship between variations of the NA stream and Arctic sea ice in a warming climate is a topic of ongoing research.

Acknowledgments. The authors thank three anonymous reviewers for their valuable comments that have led to an improved manuscript. This study was supported in part by the Japanese Ministry of Education, Culture, Sports, Science and Technology through a Grant-in-Aid $15 \mathrm{H} 02129$ and by the Social Implementation Program on Climate Change Adaptation Technology (SI-CAT). YK is supported by Japan Society for the Promotion of Science through a Grant-in-Aid for Research Fellow (16J01722). JW is supported by NOAA's Climate Program Office through Grants NA15OAR4310169 and NA16OAR4310162.

\section{REFERENCES}

Abdillah, M. R., Y. Kanno, and T. Iwasaki, 2017: Tropicalextratropical interactions associated with East Asian cold air outbreaks. Part I: Interannual variability. J. Climate, 30, 29893007, doi:10.1175/JCLI-D-16-0152.1.

Baxter, S., and S. Nigam, 2015: Key role of the North Pacific Oscillation-west Pacific pattern in generating the extreme 2013/14 North American winter. J. Climate, 28, 8109-8117, doi:10.1175/JCLI-D-14-00726.1.

Burnett, A. W., M. E. Kirby, H. T. Mullins, and W. P. Patterson, 2003: Increasing Great Lake-effect snowfall during the twentieth century: A regional response to global warming? 
J. Climate, 16, 3535-3542, doi:10.1175/1520-0442(2003)016<3535: IGLSDT $>2.0 . C O ; 2$.

Cellitti, M. P., J. E. Walsh, R. M. Rauber, and D. H. Portis, 2006: Extreme cold air outbreaks over the United States, the polar vortex, and the large-scale circulation. J. Geophys. Res., 111, D02114, doi:10.1029/2005JD006273.

Dallavalle, J. P., and L. F. Bosart, 1975: A synoptic investigation of anticyclogenesis accompanying North American polar air outbreaks. Mon. Wea. Rev., 103, 941-957, doi:10.1175/ 1520-0493(1975)103<0941:ASIOAA > 2.0.CO;2.

Easterling, D. R., T. R. Karl, J. H. Lawrimore, and S. A. Del Greco, 1999: United States historical climatology network daily temperature, precipitation, and snow data for 1871-1997. NOAA/Oak Ridge National Laboratory/Environmental Sciences Division Publ. 4887, 94 pp., http://info.ornl.gov/sites/ publications/Files/Pub57691.pdf.

Garreaud, R. D., 2001: Subtropical cold surges: Regional aspects and global distribution. Int. J. Climatol., 21, 1181-1197, doi:10.1002/joc.687.

Grotjahn, R., and G. Faure, 2008: Composite predictor maps of extraordinary weather events in the Sacramento, California, region. Wea. Forecasting, 23, 313-335, doi:10.1175/ 2007WAF2006055.1.

Hartjenstein, G., and R. Bleck, 1991: Factors affecting coldair outbreaks east of the Rocky Mountains. Mon. Wea Rev., 119, 2280-2292, doi:10.1175/1520-0493(1991)119<2280: FACAOE $>2.0 . \mathrm{CO} ; 2$

Hurrell, J. W., 1995: Decadal trends in the North Atlantic Oscillation: Regional temperatures and precipitation. Science, $\mathbf{2 6 9}$, 676-679, doi:10.1126/science.269.5224.676.

Iwasaki, T., T. Shoji, Y. Kanno, M. Sawada, M. Ujiie, and K. Takaya, 2014: Isentropic analysis of polar cold airmass streams in the Northern Hemispheric winter. J. Atmos. Sci. 71, 2230-2243, doi:10.1175/JAS-D-13-058.1.

Kanno, Y., T. Shoji, and T. Iwasaki, 2015: Comparison study of the polar cold air mass between Northern and Southern Hemispheric winters based on a zonal-mean two-box model. Atmos. Sci. Lett., 16, 70-76, doi:10.1002/asl2.522.

_ , M. R. Abdillah, and T. Iwasaki, 2016: Long-term trend of cold air mass amount below a designated potential temperature in Northern and Southern Hemispheric winters using reanalysis data sets. J. Geophys. Res. Atmos., 121, 10138 10152 , doi:10.1002/2015JD024635.

Kobayashi, S., and Coauthors, 2015: The JRA-55 Reanalysis: General specifications and basic characteristics. J. Meteor Soc. Japan, 93, 5-48, doi:10.2151/jmsj.2015-001.

Kolstad, E. W., T. Breiteig, and A. A. Scaife, 2010: The association between stratospheric weak polar vortex events and cold air outbreaks in the Northern Hemisphere. Quart. J. Roy. Meteor. Soc., 136, 886-893, doi:10.1002/qj.620.

Konrad, C. E., 1996: Relationships between the intensity of cold-air outbreaks and the evolution of synoptic and planetary-scale features over North America. Mon. Wea. Rev., 124, 1067-1083, doi:10.1175/1520-0493(1996)124<1067: RBTIOC $>2.0 . \mathrm{CO} ; 2$

__ 1998: Persistent planetary scale circulation patterns and their relationship with cold air outbreak activity over the eastern United States. Int. J. Climatol., 18, 1209-1221, doi:10.1002/ (SICI)1097-0088(199809)18:11<1209::AID-JOC301>3.0.CO;2-K.

Kug, J. S., J. H. Jeong, Y. S. Jang, B. M. Kim, C. K. Folland, S. K. Min, and S. W. Son, 2015: Two distinct influences of Arctic warming on cold winters over North America and East Asia. Nat. Geosci., 8, 759-762, doi:10.1038/ngeo2517.
Lee, M.-Y., C.-C. Hong, and H.-H. Hsu, 2015: Compounding effects of warm sea surface temperature and reduced sea ice on the extreme circulation over the extratropical North Pacific and North America during the 2013-2014 boreal winter. Geophys. Res. Lett., 42, 1612-1618, doi:10.1002/ 2014GL062956.

Mailler, S., and F. Lott, 2010: Equatorial mountain torques and cold surge preconditioning. J. Atmos. Sci., 67, 2101-2120, doi:10.1175/2010JAS3382.1.

Marinaro, A., S. Hilberg, D. Changnon, and J. R. Angel, 2015: The North Pacific-driven severe Midwest winter of 2013/ 14. J. Appl. Meteor. Climatol., 54, 2141-2151, doi:10.1175/ JAMC-D-15-0084.1.

Martin, J. E., 2015: Contraction of the Northern Hemisphere, lower-tropospheric, wintertime cold pool over the past 66 years. J. Climate, 28, 3764-3778, doi:10.1175/ JCLI-D-14-00496.1.

Minobe, S., A. Kuwano-Yoshida, N. Komori, S. P. Xie, and R. J. Small, 2008: Influence of the Gulf Stream on the troposphere. Nature, 452, 206-209, doi:10.1038/nature06690.

Mo, K. C., and R. E. Livezey, 1986: Tropical-extratropical geopotential height teleconnections during the Northern Hemisphere winter. Mon. Wea. Rev., 114, 2488-2515, doi:10.1175/ 1520-0493(1986)114<2488:TEGHTD $>2.0$. CO 2 .

Navarra, A., and V. Simoncini, 2010: A Guide to Empirical Orthogonal Functions for Climate Data Analysis. 1st ed. Springer Netherlands, $151 \mathrm{pp}$.

O'Connor, J. F., 1963: The weather and circulation of January 1963: One of the most severe months on record in the United States or Europe. Mon. Wea. Rev., 91, 209-218, doi:10.1175/ 1520-0493(1963)091<0209:TWACOJ >2.3.CO;2.

Ogi, M., S. Rysgaard, and D. G. Barber, 2016: Cold winter over North America: The influence of the East Atlantic (EA) and the tropical/Northern Hemisphere (TNH) teleconnection patterns. Open Atmos. Sci. J., 10, 6-13, doi:10.2174/ 1874282301610010006

Overland, J. E., J. A. Francis, R. Hall, E. Hanna, S.-J. Kim, and T. Vihma, 2015: The melting Arctic and midlatitude weather patterns: Are they connected? J. Climate, 28, 7917-7932, doi:10.1175/JCLI-D-14-00822.1.

Rogers, J. C., 1984: The association between the North Atlantic Oscillation and the Southern Oscillation in the Northern Hemisphere. Mon. Wea. Rev., 112, 1999-2015, doi:10.1175/ 1520-0493(1984)112<1999:TABTNA > 2.0.CO;2. , and R. V. Rohli, 1991: Florida citrus freezes and polar anticyclones in the Great Plains. J. Climate, 4, 1103-1113, doi:10.1175/1520-0442(1991)004<1103:FCFAPA > 2.0.CO;2.

Schultz, D. M., W. E. Bracken, and L. F. Bosart, 1998: Planetaryand synoptic-scale signatures associated with Central American cold surges. Mon. Wea. Rev., 126, 5-27, doi:10.1175/ 1520-0493(1998)126<0005:PASSSA $>2.0 . \mathrm{CO} ; 2$.

Shoji, T., Y. Kanno, T. Iwasaki, and K. Takaya, 2014: An isentropic analysis of the temporal evolution of East Asian cold air outbreaks. J. Climate, 27, 9337-9348, doi:10.1175/ JCLI-D-14-00307.1.

Takaya, K., and H. Nakamura, 2013: Interannual variability of the East Asian winter monsoon and related modulations of the planetary waves. J. Climate, 26, 9445-9461, doi:10.1175/ JCLI-D-12-00842.1.

Thompson, D. W. J., and J. M. Wallace, 1998: The Arctic Oscillation signature in the wintertime geopotential height and temperature fields. Geophys. Res. Lett., 25, 1297-1300, doi:10.1029/98GL00950. 
and - 2001: Regional climate impacts of the Northern Hemisphere annular mode. Science, 293, 85-89, doi:10.1126/ science.1058958.

- M. P. Baldwin, and J. M. Wallace, 2002: Stratospheric connection to Northern Hemisphere wintertime weather: Implications for prediction. J. Climate, 15, 1421-1428, doi:10.1175/ 1520-0442(2002)015<1421:SCTNHW >2.0.CO;2.

Wallace, J. M., and D. S. Gutzler, 1981: Teleconnections in the geopotential height field during the Northern Hemisphere winter. Mon. Wea. Rev., 109, 784-812, doi:10.1175/1520-0493(1981)109<0784: TITGHF $>2.0 . \mathrm{CO} ; 2$.
Walsh, J. E., A. S. Phillips, D. H. Portis, and W. L. Chapman, 2001: Extreme cold outbreaks in the United States and Europe, 1948-99. J. Climate, 14, 2642-2658, doi:10.1175/1520-0442(2001)014<2642: ECOITU $>2.0 . \mathrm{CO} ; 2$.

Yu, B., X. Zhang, H. Lin, and J.-Y. Yu, 2015: Comparison of wintertime North American climate impacts associated with multiple ENSO indices. Atmos.-Ocean, 53, 426-445, doi:10.1080/07055900.2015.1079697.

Yu, J.-Y., Y. Zou, S. T. Kim, and T. Lee, 2012: The changing impact of El Niño on US winter temperatures. Geophys. Res. Lett., 39, L15702, doi:10.1029/2012GL052483. 